\title{
Assessment of the Agreement level of Folliculometry Performed by Trained Nurses versus Infertility Clinicians
}

\author{
Eman R Ahmad \& Haifa A Al-Turki \\ Obstetric and Gynecologic Nursing Department, Faculty of Nursing, Assiut University, Egypt. \\ Maternity and Child Health Nursing, Faculty of Nursing, University of Dammam, Kingdom of Saudi Arabia. \\ Department of Obstetrics and Gynecology, College of Medicine, University of Dammam, Kingdom of Saudi Arabia.
}

\begin{abstract}
Background: Nurses can achieve competence in performing Folliculometry (FM) during ovarian stimulation cycles (OSC) within a reasonable timeframe. However limited information is available regarding the difference in the folliculometry performance between nurses and physicians in Arab countries. Aim: The aim of this study was to assess the level of agreement of the Folliculometry Scans (FS) performed by trained nurses compared to infertility clinicians. Subjects and Methods: A quazi experimental (Counterbalanced design) was conducted in the Obstetrics and Gynecology/Ultrasongraphy Unit at King Fahd Hospital University-Saudi Arabia for 104 eligible infertile consecutive patients performed 346 ultrasound scans by 6 postgraduates OBGYN nurses and 6 infertility clinicians. The nurse had hands on training given by expert infertility consultants for 8 sessions. Two tools were used for data collection, a checklist observation sheet to assess the performance of the nurses before starting the study, and the $2^{\text {nd }}$ tool was the observation of follicular Scan (FS) findings of all raters. Results: Almost perfect agreement was observed between both raters regarding all FS quantitative and qualitative uterine and ovarian values at different times of menstrual cycle.Conclusion: With appropriate training and supervision, the nurse can perform FS and interpret the quantitative and qualitative findings with high level of agreement and accuracy similar to that obtained by infertility clinicians.
\end{abstract}

\section{Keywords: Folliculometry; Inter-rater Agreement; Inter-Rater, Accuracy \& Infertile Women.}

\section{Introduction}

In the past decades it was observed that there was exemplary proliferation of roles other than clinical or "bedside" nursing to include many functions which nurses could participate and perform well in the routine patient care. Janelle (2002) suggested that even though the nurses could be utilized to perform many patient care related function, their services still remain under-utilized. In the recent past contributions of nurses to infertility programs, their roles have expanded to the extent that it has been coined as 'the birth of a specialism' and officially recognized in the United Kingdom by the formation of the Infertility Nurses Group of the Royal College of Nursing. Carr (2011) reported that in many In Vitro Fertilization (IVF) units nurses form an important professional group with whom couples have most contact during treatment.

According to the Bureau of Labor Statistics (2006) the demand for Advanced Practice Registered Nurses (APNs) is expected to continue to increase over the next decade and beyond, as the need and demand for effective health care increases, especially in rural, inner-city, and other underserved areas.

American Institute of Ultrasound in Medicine (2012) emphasized that nurses, midwives and nurse practitioners working in obstetrics, gynecology, and/or assisted reproductive technologies are incorporating ultrasound skills into their everyday practice. Moreover, Morris (2009) studied the role of infertility nurses in ovulation induction programs, and found that in $39 \%$ of units, nurses performed intrauterine inseminations, in $23 \%$ of units they took decisions as to institute hormonal therapy like human chorionic gonadotrophin administration, and in $77 \%$ of units transvaginal scans were done by nurses.

As Ultrasound Folliculometry is a serial of transvaginal ultrasound scan test carried out to monitor follicular growth, it is one of the most accurate methods for determining ovulation. Other useful information which can be determined by these scans is the thickness of the endometrium. (National Institute for Health \& Care Excellence (2013) and Rodriguez (2014). Furthermore, it has long been argued that the nurse, by virtue of her gender (most nurses being females) and training, is more likely to be capable of providing sensitive and empathic support to infertile women as well as education and counseling to the couple. American Institute for US in Medicine (2009) \& Barnhart (2000) As women in Gynecological clinic prefer to be examined by female health care provider rather than males for that, availability of well-trained female nurses in the infertility clinic to do folliculometry ultrasonography (FMUS) in proper way is highly recommended. Moreover, the performance of a limited pelvic ultrasound examination is within the scope practice for a nurse having the necessary specific training and appropriate supervision by a physician (s) in an infertility practice, it provides specific rather than 
complete, diagnostic information relating to the organ measurement (s) of interest, such as the size and number of developing ovarian follicles or the endometrial thickness and pattern. American Society for Reproductive Medicine (2009) \& Royal College of Nursing (2012)

There are no reports from the Gulf region on the subject, hence this study was undertaken to firstly assess whether the nurse if received appropriate training could had acceptable level of agreement and accuracy in performing and interpreting folliculometry as an infertility clinician and secondly to establish training program in which nurses could be empowered to practice transvaginal ultrasonography independently.

\section{Aim of the work}

The aim of this study was to assess the level of agreement of the Folliculometry Scans (FS) performed by trained nurses compared to infertility clinicians.

Research question:

Can the trained nurses do folliculometry scan in acceptable agreement to infertility clinicians?

Method

Study design: A quazi experimental (Counterbalanced design) was used in this study.

Setting: The study was carried out in the obstetrics and Gynecology emergency/ ultrasongraphy-Unit at King Fahd University Hospital, University of Dammam, Eastern Province of Saudi Arabia. This hospital was chosen, as it is a teaching, tertiary level care hospital with high turnover patients who had fertility problems. It provides fertility services for approximately 1200 women annually as the folliculometry clinic providing its services 3 days a week for approximately 7-10 cases per day.

\section{Study population}

A total of 346 folliculometry scan is considered as a sample unit for the study that was performed by postgraduate nurse and infertility clinicians for 104 eligible women who were recruited in this study. The study started at Jan. to Dec. 2013 in King Fahd Hospital at Dammam University in Al-khobar, Saudi Arabia as part of an ongoing larger US training Program for nurses. The FS was conducted by 6 postgraduates OBGYN nurses who didn't have any prior ultrasonography experience or even attending any US courses before receiving the training sessions versus 6 infertility clinicians who had good experience in Folliculometry and practiced it independently. The eligible infertile women were examined at different times of their cycles. Baseline scan represent the time between the 3rd to 5th day of menstruation, 8th day of cycle and midcycle day for more than one cycle throughout 1 year follow-up. Study question: Can nurses with no previous experience in transvaginal ultrasound learn to perform folliculometry with 2D transvaginal ultrasound during ovarian stimulation cycles in acceptable agreement as infertility clinicians?

\section{Ethical considerations}

The study was approved by the ethical committee and research committee of University of Dammam. Before the patient was scanned, she was notified of:

- The aim, methods, anticipated benefits and potential hazards of the research.

- Right to abstain from participation in the research and her right to terminate the participation at any time. No pressure or inducement of any kind was applied to encourage the patients to be part of the study. An informed written consent was obtained.

- The identity of patients in the study was kept strictly confidential.

Tools: One tool was developed by researcher and used for data collection named assessment tool, it entailed 4 parts covered the following items:

Part I: Demographic data of the infertile women which includes women age, education level, duration of marriage etc.

Part II: Infertility History and treatment regimen which denotes types of infertility, duration of received fertility medication, history of smoking and its type and hormonal profile.

Part III: Observational Checklist for auditing nurses performance which includes assessment of the following items; Preparation of the patient, operating of ultrasonography device, application of vaginal probe. Evaluating base line scan findings as position of the uterus.

Part IV: Direct observation assessment tool used by both raters for assessing the uterine, ovarian findings and any accompanying pathologies. Data related folliculometry were documented in separate sheet by both raters.

\section{Procedure}

In order to conduct the study, 3 phases were accomplished, in the first phase the postgraduate OBGYN nurses received cognitive learning that was conducted to understand the physics, principles, applications, and clinical significance of ultrasonography which imparted through traditional media such as lectures and textbooks, in which 2 lectures were taken each took 2 hours. In the Second phase, a total of 8 sessions in which visual pattern recognition was accomplished by attending several sessions, these sessions were repetitive, nonverbal and arranged as (3 sessions observation only, 3 sessions partial dependence of performing folliculometry and 2 sessions independent performance) each session took approximately 1 hour that were done 3 days weekly according to the availability of cases in which the nurses assigned for 
variable steps of folliculometry and the evaluation was run through application of the checklist for auditing of their performance which was evaluated by 2 independent assessors who are expert in folliculometry. The third phase was designed to assess both raters performance in which the postgraduate nurses and the infertility clinicians started folliculometry scan on the same setting where the comparison was enrolled between both of them.

The infertility clinician started to do the folliculometry for the woman and_recorded the findings in separate sheet then followed by the prepared nurse started it to the same patient and also recorded the findings in a separate sheet. Comment on the presence of any cysts or masses and document the number of antral follicles and measuring the dominant one in natural cycle or multiples in induced cycle. To complete the follicular tracking both nurses and physicians took all measurements on the follicular scan at different times of the menstrual cycle (base line scan at 3-5 days, midcycle 8-12 day and at 13-17 day). All blinded findings documented in separate sheet for statistical analysis.

\section{Data collection and analysis}

Inter-rater agreement of follicular scan measurements $\&$ observation between nurses and physicians was done using Kappa test \& diagnostic accuracy of folliculometry. Inter-rater (or inter-observer) reliability is estimated by having two observers watching an event simultaneously, and independently recording data according to their observation (Table 1). The data can be used to compute an index of equivalence or agreement between observers. Kappa statistics for the estimation of inter observer reliability was used and the variable under study has underlying continuity non parametric statistical testes apply to data in an ordinal scale. A correlation coefficient is computed to demonstrate the strength of the relationship between one observer's ratings and another's (Figure 1).

\begin{tabular}{|l|l|c|}
\hline Value of Kappa & $\begin{array}{c}\text { Level of } \\
\text { Agreement }\end{array}$ & $\begin{array}{c}\text { Percentage (\%) of Data } \\
\text { that are Reliable }\end{array}$ \\
\hline \hline $\mathbf{0 - 0 . 2 0}$ & None & $0-4 \%$ \\
\hline $\mathbf{0 . 2 1 - 0 . 3 9}$ & Minimal & $4-15 \%$ \\
\hline $\mathbf{0 . 4 0 - 0 . 5 9}$ & Weak & $15-35 \%$ \\
\hline $\mathbf{0 . 6 0 - 0 . 7 9}$ & Moderate & $35-63 \%$ \\
\hline $\mathbf{0 . 8 0 - 0 . 9 0}$ & Strong & $64-81 \%$ \\
\hline Above 0.090 & $\begin{array}{c}\text { Almost } \\
\text { Perfect }\end{array}$ \\
\hline
\end{tabular}

Figure(1): Interpretation of Cohen's Kappa. Marry (2012)

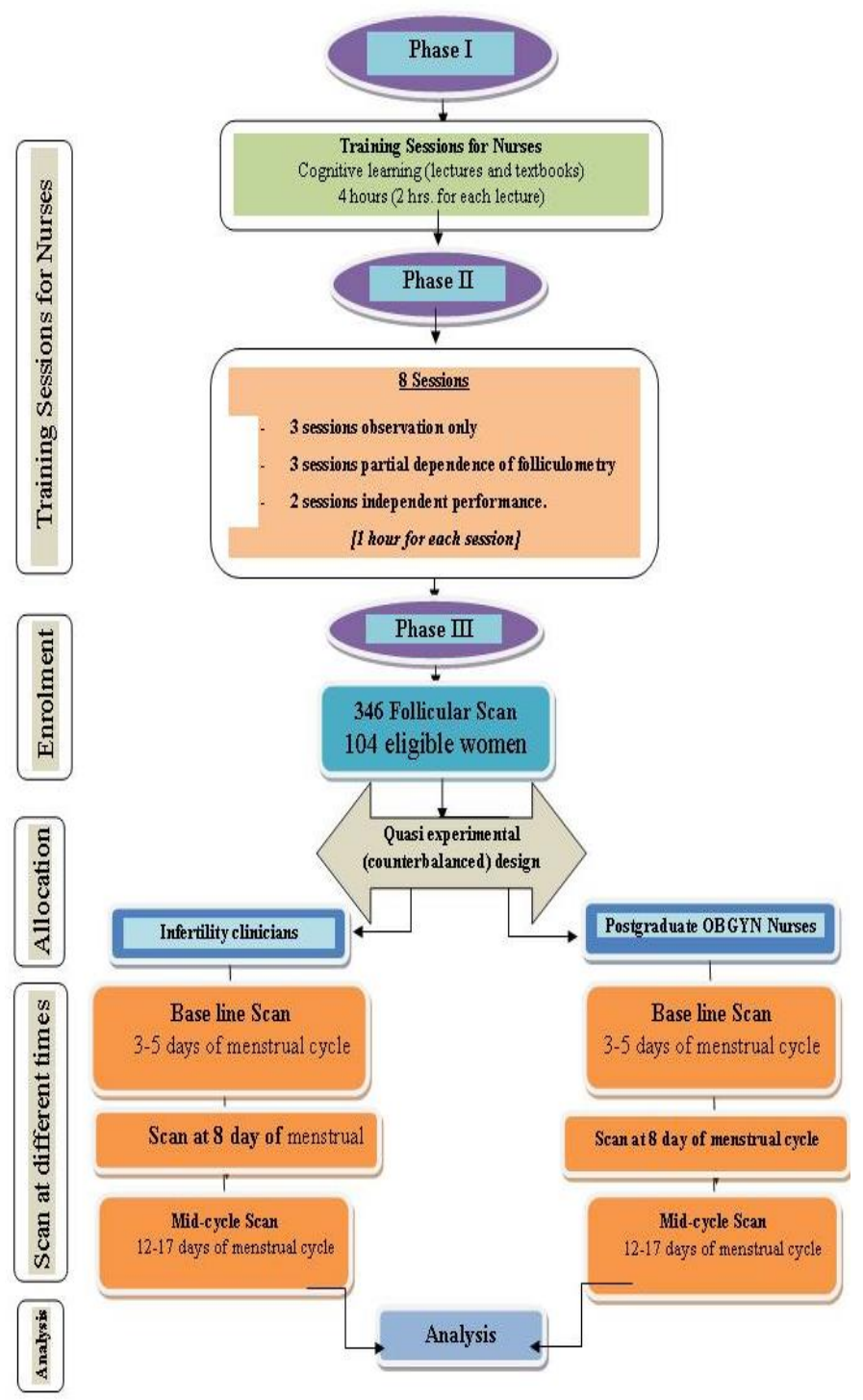

Figure (2): Flow Chart of folliculometry Performance 


\section{Results}

Table (1): Inter-rater agreement of follicular scan measurements between infertility clinicians and postgraduate OBGYN nurses.

\begin{tabular}{|c|c|c|c|c|c|c|c|}
\hline \multirow[t]{2}{*}{ Item } & \multicolumn{2}{|c|}{$\begin{array}{c}\text { Performance of } \\
\text { infertility clinician }\end{array}$} & \multicolumn{2}{|c|}{$\begin{array}{c}\text { Performance of } \\
\text { postgraduate OBGYN } \\
\text { nurses }\end{array}$} & \multirow[t]{2}{*}{ P. value } & \multirow[t]{2}{*}{$\mathbf{R}$} & \multirow{2}{*}{$\begin{array}{c}\text { Mean \% } \\
\text { of } \\
\text { Absolute } \\
\text { error }\end{array}$} \\
\hline & $\underset{\text { SD }}{\operatorname{Mean} \pm}$ & Median & Mean \pm SD & Median & & & \\
\hline \multicolumn{8}{|c|}{ Base-line scan (2 - 5 day of cycle) } \\
\hline $\begin{array}{l}\text {-Uterine Findings } \\
\text { Length of the uterus }\end{array}$ & $7.48 \pm 1.19$ & 7.3 & $7.49 \pm 1.22$ & 7.5 & 0.910 & 0.961 & 2.7 \\
\hline Width of the uterus & $4.17 \pm 0.63$ & 4.2 & $4.15 \pm 0.63$ & 4.3 & 0.874 & 0.943 & 3.6 \\
\hline Endometrial thickness & $5.65 \pm 1.62$ & 5.4 & $5.67 \pm 1.61$ & 5.5 & 0.981 & 0.962 & 5.1 \\
\hline $\begin{array}{l}\text {-Rt Ovarian Findings } \\
\text { Length of Rt. Ovary }\end{array}$ & $3.3 \pm 0.68$ & 3.3 & $3.34 \pm 0.7$ & 3.4 & 0.887 & 0.957 & 4.7 \\
\hline Width of Rt. Ovary & $2.3 \pm 0.67$ & 2.3 & $2.36+0.71$ & 2.3 & 0.775 & 0.970 & 5.6 \\
\hline $\begin{array}{l}\text { No. of Rt. Ovarian } \\
\text { follicles }\end{array}$ & $7.09 \pm 2.78$ & 7.0 & $6.93 \pm 2.64$ & 7.0 & 0.679 & 0.973 & 4.2 \\
\hline $\begin{array}{l}\text { Measurement of } \\
\text { dominant follicle }\end{array}$ & $3.48 \pm 7.19$ & 0.0 & $3.53 \pm 7.08$ & 0.0 & 0.662 & 0.993 & 7.4 \\
\hline $\begin{array}{l}\text {-Lt Ovarian Findings } \\
\text { Length of Lt. ovary }\end{array}$ & $3.12 \pm 0.86$ & 3.0 & $3.13 \pm 0.85$ & 3.0 & 0.989 & 0.976 & 4.7 \\
\hline Width of Lt. ovary & $2.18 \pm 0.65$ & 2.1 & $2.2 \pm 0.67$ & 2.1 & 0.884 & 0.947 & 6.8 \\
\hline $\begin{array}{l}\text { No. of Lt. ovarian } \\
\text { follicles }\end{array}$ & $6.67 \pm 2.76$ & 6.0 & $6.8+2.84$ & 6.0 & 0.929 & 0.973 & 5.0 \\
\hline $\begin{array}{l}\text { Measurement of } \\
\text { dominant follicle }\end{array}$ & $2.19 \pm 6.25$ & 0.0 & $2.21 \pm 6.08$ & 0.0 & 0.757 & 0.992 & 4.1 \\
\hline \multicolumn{8}{|c|}{ Ultrasound scan on (8 - 12 day of cycle) } \\
\hline $\begin{array}{l}\text {-Uterine Findings } \\
\text { Endometrial thickness }\end{array}$ & $7.32 \pm 1.75$ & 7.2 & $7.46 \pm 1.8$ & 7.5 & 0.542 & 0.956 & 4.1 \\
\hline $\begin{array}{l}\text { Rt. Ovarian Findings } \\
\text { No. of Rt. Ovarian } \\
\text { follicles }\end{array}$ & $6.96 \pm 2.85$ & 7.0 & $6.99 \pm 2.67$ & 7.0 & 0.779 & 0.968 & 5.8 \\
\hline $\begin{array}{l}\text { Measurement of } \\
\text { dominant follicle }\end{array}$ & $8.39 \pm 6.71$ & 10.5 & $8.71 \pm 6.97$ & 11.0 & 0.662 & 0.994 & 6.0 \\
\hline $\begin{array}{l}\text { Lt. Ovarian Findings } \\
\text { No. of Lt. ovarian } \\
\text { follicles }\end{array}$ & $6.67 \pm 2.48$ & 6.0 & $6.81 \pm 2.58$ & 6.0 & 0.883 & 0.951 & 5.0 \\
\hline $\begin{array}{l}\text { Measurement of } \\
\text { dominant follicle }\end{array}$ & $7.92 \pm 6.8$ & 10.5 & $8.21 \pm 7.03$ & 10.5 & 0.573 & 0.993 & 6.7 \\
\hline \multicolumn{8}{|c|}{ Ultrasound scan on (13 - 17 day of cycle) } \\
\hline $\begin{array}{l}\text {-Uterine Findings } \\
\text { Endometrial thickness } \\
\end{array}$ & $7.91 \pm 2.15$ & 7.8 & $7.94 \pm 2.09$ & 7.8 & 0.911 & 0.980 & 3.0 \\
\hline $\begin{array}{l}\text {-Rt. Ovarian Findings } \\
\text { No. of Rt. Ovarian } \\
\text { follicles }\end{array}$ & $6.55 \pm 3.17$ & 5.0 & $6.67 \pm 3.22$ & 5.5 & 0.881 & 0.986 & 3.8 \\
\hline $\begin{array}{l}\text { Measurement of } \\
\text { dominant follicle }\end{array}$ & $9.58 \pm 7.49$ & 12.0 & $9.7 \pm 7.52$ & 12.5 & 0.782 & 0.994 & 5.5 \\
\hline $\begin{array}{l}\text {-Lt. Ovarian Findings } \\
\text { No. of Lt. ovarian } \\
\text { follicles }\end{array}$ & $6.58 \pm 3$ & 6.0 & $6.57 \pm 3.05$ & 6.0 & 0.994 & 0.984 & 4.5 \\
\hline
\end{tabular}


Table (2): Inter-rater agreement of Base-line follicular scan findings (observations) between infertility clinicians and postgraduate OBGYN nurses.

\begin{tabular}{|c|c|c|c|c|}
\hline & $\begin{array}{l}\text { Performance of } \\
\text { infertility clinician }\end{array}$ & $\begin{array}{c}\text { Performance of } \\
\text { postgraduate OBGYN } \\
\text { nurses }\end{array}$ & Kappa & Accuracy \\
\hline $\begin{array}{l}\text { Uterine findings } \\
\text { - Position of the uterus } \\
\text { Anteverted }\end{array}$ & 90 & 91 & \multirow[t]{2}{*}{0.97} & \multirow[t]{2}{*}{99.1} \\
\hline Retroverted & 23 & 22 & & \\
\hline \multicolumn{5}{|l|}{ - $\quad$ Evidence of uterine fibroid } \\
\hline Yes & 10 & 10 & \multirow{2}{*}{1.00} & \multirow{2}{*}{100.0} \\
\hline No & 103 & 103 & & \\
\hline \multicolumn{5}{|l|}{$\begin{array}{l}\text { Rt. Ovarian findings } \\
\text { - Visualization of the ovary }\end{array}$} \\
\hline Yes & 105 & 105 & \multirow{2}{*}{1.00} & \multirow{2}{*}{100.0} \\
\hline No & 8 & 8 & & \\
\hline \multicolumn{5}{|l|}{$\begin{array}{l}\text { Documentation of ovarian } \\
\text { response }\end{array}$} \\
\hline Yes & 8 & 18 & \multirow{2}{*}{0.57} & \multirow{2}{*}{91.2} \\
\hline No & 105 & 95 & & \\
\hline \multicolumn{5}{|l|}{ - $\quad$ Evidence of PCO picture } \\
\hline Yes & 25 & 25 & \multirow{2}{*}{1.00} & \multirow{2}{*}{100.0} \\
\hline No & 88 & 88 & & \\
\hline \multicolumn{5}{|l|}{$\begin{array}{l}\text { Lt. Ovarian findings } \\
\text { - } \quad \text { Visualized }\end{array}$} \\
\hline Yes & 109 & 107 & \multirow{2}{*}{0.79} & \multirow{2}{*}{98.2} \\
\hline No & 4 & 6 & & \\
\hline \multicolumn{5}{|l|}{ - $\quad$ Response } \\
\hline Yes & 9 & 17 & \multirow{2}{*}{0.66} & \multirow{2}{*}{92.9} \\
\hline No & 103 & 95 & & \\
\hline \multicolumn{5}{|l|}{ - $\quad$ Evidence of ovarian cyst } \\
\hline Yes & 13 & 11 & \multirow{2}{*}{0.91} & \multirow{2}{*}{98.2} \\
\hline No & 100 & 102 & & \\
\hline
\end{tabular}

Table (3): Inter-rater agreement of follicular scan findings at 8-12 days of cycle (observations) between infertility consultant and academic nurse.

\begin{tabular}{|c|c|c|c|c|}
\hline & $\begin{array}{c}\text { Performance of } \\
\text { infertility clinicians }\end{array}$ & $\begin{array}{c}\text { Performance of } \\
\text { postgraduate OBGYN } \\
\text { nurses }\end{array}$ & Kappa & Accuracy \\
\hline \multicolumn{5}{|c|}{$\begin{array}{l}\text { Uterine findings } \\
-\quad \text { Position of the uterus }\end{array}$} \\
\hline Anteverted & 131 & 131 & \multirow[t]{2}{*}{0.94} & \multirow[t]{2}{*}{98.7} \\
\hline Retroverted & 21 & 21 & & \\
\hline \multicolumn{5}{|c|}{ - $\quad$ Evidence of uterine fibroid } \\
\hline Yes & 6 & 5 & \multirow[t]{2}{*}{0.91} & \multirow[t]{2}{*}{99.3} \\
\hline No & 146 & 147 & & \\
\hline \multicolumn{5}{|c|}{$\begin{array}{l}\text { Rt. Ovarian findings } \\
\text { - Visualized } \\
\end{array}$} \\
\hline Yes & 151 & 151 & \multirow[t]{2}{*}{1.00} & \multirow[t]{2}{*}{100.0} \\
\hline No & 1 & 1 & & \\
\hline
\end{tabular}




\begin{tabular}{|c|c|c|c|c|}
\hline & $\begin{array}{c}\text { Performance of } \\
\text { infertility clinicians }\end{array}$ & $\begin{array}{c}\text { Performance of } \\
\text { postgraduate OBGYN } \\
\text { nurses }\end{array}$ & Kappa & Accuracy \\
\hline Yes & 75 & 84 & \multirow[t]{2}{*}{0.88} & \multirow[t]{2}{*}{94.1} \\
\hline No & 77 & 68 & & \\
\hline \multicolumn{5}{|c|}{ - $\quad$ Evidence of PCO picture } \\
\hline Yes & 12 & 12 & \multirow[t]{2}{*}{1.00} & \multirow[t]{2}{*}{100.0} \\
\hline No & 140 & 140 & & \\
\hline \multicolumn{5}{|c|}{ - $\quad$ Evidence of ovarian cyst } \\
\hline Yes & 5 & 7 & \multirow[t]{2}{*}{0.83} & \multirow[t]{2}{*}{98.7} \\
\hline No & 147 & 145 & & \\
\hline \multicolumn{5}{|c|}{$\begin{array}{l}\text { Lt. Ovarian findings } \\
\text { Visualized }\end{array}$} \\
\hline Yes & 142 & 141 & \multirow[t]{2}{*}{0.95} & \multirow[t]{2}{*}{99.3} \\
\hline No & 10 & 11 & & \\
\hline \multicolumn{5}{|l|}{ Response } \\
\hline Yes & 64 & 69 & \multirow[t]{2}{*}{0.93} & \multirow[t]{2}{*}{96.7} \\
\hline No & 87 & 82 & & \\
\hline \multicolumn{5}{|c|}{ Evidence of ovarian cyst } \\
\hline Yes & 4 & 5 & \multirow[t]{2}{*}{0.89} & \multirow[t]{2}{*}{99.3} \\
\hline No & 148 & 147 & & \\
\hline
\end{tabular}

Table (4): Inter-rater agreement of follicular scan findings at 13-17 days of cycle (observations) between infertility consultant and postgraduate OBGYN nurses.

\begin{tabular}{|c|c|c|c|c|}
\hline & $\begin{array}{c}\text { Performance of } \\
\text { infertility clinicians }\end{array}$ & $\begin{array}{l}\text { Performance of } \\
\text { postgraduate } \\
\text { OBGYN nurses }\end{array}$ & Kappa & Accuracy \\
\hline \multicolumn{5}{|c|}{$\begin{array}{l}\text { Uterine findings } \\
\text { - Position of the uterus }\end{array}$} \\
\hline Anteverted & 61 & 59 & \multirow[t]{2}{*}{0.87} & \multirow[t]{2}{*}{97.1} \\
\hline Retroverted & 8 & 10 & & \\
\hline \multicolumn{5}{|c|}{ - $\quad$ Ensure fluids in the Cul De Sac } \\
\hline Yes & 2 & 3 & \multirow[t]{2}{*}{0.79} & \multirow[t]{2}{*}{98.6} \\
\hline No & 67 & 66 & & \\
\hline \multicolumn{5}{|c|}{ - $\quad$ Evidence of uterine fibroid } \\
\hline Yes & 0 & 0 & \multirow[t]{2}{*}{ NA } & \multirow[t]{2}{*}{100.0} \\
\hline No & 69 & 69 & & \\
\hline \multicolumn{5}{|c|}{$\begin{array}{l}\text { Rt. Ovarian findings } \\
\text { - Visualized }\end{array}$} \\
\hline Yes & 68 & 68 & \multirow[t]{2}{*}{1.00} & \multirow[t]{2}{*}{100.0} \\
\hline No & 1 & 1 & & \\
\hline \multicolumn{5}{|l|}{ - $\quad$ Response } \\
\hline Yes & 39 & 41 & \multirow[t]{2}{*}{0.94} & \multirow[t]{2}{*}{97.1} \\
\hline No & 29 & 27 & & \\
\hline \multicolumn{5}{|c|}{ Evidence of PCO picture } \\
\hline Yes & 4 & 4 & \multirow[t]{2}{*}{1.00} & \multirow[t]{2}{*}{100.0} \\
\hline No & 65 & 65 & & \\
\hline \multicolumn{5}{|c|}{ - $\quad$ Evidence of ovarian cyst } \\
\hline Yes & 6 & 6 & \multirow[t]{2}{*}{1.00} & \multirow[t]{2}{*}{100.0} \\
\hline No & 63 & 63 & & \\
\hline
\end{tabular}




\begin{tabular}{|c|c|c|c|c|}
\hline & $\begin{array}{c}\text { Performance of } \\
\text { infertility clinicians }\end{array}$ & $\begin{array}{c}\text { Performance of } \\
\text { postgraduate } \\
\text { OBGYN nurses }\end{array}$ & Kappa & Accuracy \\
\hline \multicolumn{5}{|c|}{$\begin{array}{l}\text { Lt. Ovarian findings } \\
\text { - Visualized }\end{array}$} \\
\hline Yes & 66 & 65 & \multirow[t]{2}{*}{0.85} & \multirow[t]{2}{*}{98.6} \\
\hline No & 3 & 4 & & \\
\hline Response & \multirow{2}{*}{26} & \multirow{2}{*}{26} & \multirow{3}{*}{1.00} & \multirow{3}{*}{100.0} \\
\hline Yes & & & & \\
\hline No & 42 & 42 & & \\
\hline \multicolumn{5}{|c|}{ - Evidence of ovarian cyst } \\
\hline Yes & 2 & 1 & \multirow[t]{2}{*}{0.66} & \multirow[t]{2}{*}{98.6} \\
\hline No & 67 & 68 & & \\
\hline
\end{tabular}

A total of 346 scan was done for 104 eligible infertile women at different times in their menstrual cycle by a total of 12 health care providers (6 postgraduate OBGYN nurses versus 6 infertility clinicians), analysis of observer or interrater agreement data often provides a useful means of assessing the reliability of a rating system. As regards the general characteristics of the eligible women of our study, it is clear that their age ranged $20-46$ years with a mean age $31.8 \pm 5.6$ years, their mean duration of marriage was $(7.7+5.3$ years) and less than one third of them had passive smoking (28.6\%); All infertile women had Folliculometry based on different times of menstrual cycle $34.6 \%$ of them are scanned as base line scan (3-5 days of menstrual cycle), $43.3 \%$ from 8-12 days and those who examined during 13th and 17 th day of menstrual cycle were $22.1 \%$.

Inter-rater agreement of follicular scan measurements at different times of the menstrual cycle presented in Table (1) shows that there is no statistically significant difference between performance of infertility clinicians and postgraduate OBGYN nurses with good agreement. In the other hand there is a very positive strong correlation nearly perfect correlation between performances of the postgraduate OBGYN nurses evident by $r$ value more than 0.9 in all parameters. Also mean value of error percentage is less than $5 \%$ in most of parameters; however the vast minority portrays that the mean value of error percentage is more than 5\% regarding measurement of the width of right \& left ovary and the dominant follicles in both ovaries. Furthermore, in Table (1) the performance of infertility clinicians and that of postgraduate OBGYN nurses are totally agreed in some parameters (kappa nearly to 1) and congruent in some parameters $(\mathrm{kappa}=1)$. Also in some parameters the accuracy is $100 \%$ percentage (congruent) and in some other parameters accuracy nearly $100 \%$ (total agreement). However, moderate to substantial agreement was observed regarding observation of fluid in cal De-sac at 13th to 17th day of scan $(0.79 \%)$. As regards qualitative ovarian findings, a total agreement was observed in visualization of right and left ovary at different times of scan, however, little agreement was portrayed regarding ovarian response especially at base line scan in the right and left ovaries evident by Kappa $(0.57 \%$ and $0.66 \%$ respectively) in Tables $\mathbf{2 \& 3}$. Furthermore, moderate agreement was observed regarding identification of ovarian cyst, Kappa was $(0.66 \%)$ as evident in Table (4).

\section{Discussion}

Nowadays the role of infertility nurse practitioners has been extended to allow more continuity of care and better understanding of patients' needs and results in the involvement of fewer people in the overall care. (Morris, 2009). Furthermore, Heidi (2009) reported that the roles of doctors and nurses should complement each other, and all practitioners should work for the benefit of patients in their care, rather than defending traditional roles and hierarchy. In this context, our study shows that with proper training a nurse could perform FS with accuracy quite similar to infertility clinicians. The study further shows that they can achieve competence in performing Folliculometry during ovarian stimulation cycles (OSC) within a reasonable timeframe Carr (2011). However in Arab countries especially in Saudi Arabia an extreme limitations and obstacles faced nurses to perform vaginal ultrasonography, this view was supported by Rodriguez et al., (2014) who reported that in spite of nurses traditionally involved in patients care and management in Assisted Reproductive Technology (ART) unit however, their role in performing ultrasound (US) is still limited. Moreover, several studies have demonstrated the extensive utility of Folliculometry Ultrasound (FMUS) scan for infertile women in the Obstetrics 
and Gynecology clinic for that, it is important to maternity nurses to be appropriately trained in its use. As regards our sample, the US scan times is considered as a sample unit for the study. The eligible infertile women have been examined according to the day of scan based on different times of menstrual cycle which reflected that comprehensive training before the commencement of the study enable the nurse to perfectly agree with the measurements obtained from the infertility clinicians as evident in inter-rater agreement of follicular scan measurements at these different times of the menstrual cycle that portrayed in Table (1) and reveals almost perfect agreements are observed between both raters (the postgraduate OBGYN nurses to infertility clinicians) regarding all follicular scan (FS) findings as kappa value near 1 in most of parameters and r-value more than 0.9 in all parameters. Another important feature in our study which warrants special mention is the mean percentage of absolute error by both postgraduate nurses and infertility clinicians (2.7-6.8) that indicates proper training of nurses can portray congruence performance compared to infertility clinicians. In our study the concordance of results between both raters shows almost perfect agreements regarding most of quantitative follicular scan (FS) that are in agreement with the findings of Sippel et al., (2011) who suggests that a short but intensive training period is sufficient for preparing clinical officers, nurses and physicians alike to perform basic ultrasound exams, especially if the training program includes both lecture and practical experience, and provides opportunity for continued upkeep of skills through review sessions and ongoing quality assurance after the training period ends. The American Society of Reproductive Medicine (ASRM) (2009) and AWHONN (2010) and Royal College of Nursing (2012) specifically supported nurses performing a limited pelvic ultrasound examination that "provides specific, rather than complete, diagnostic information relating to the organ or measurement (s) of interest" This examination includes determination of the number of developing follicles and measurement of the size of the follicles. Furthermore, Carr (2011) emphasized that appropriately trained nurses can perform limited ultrasound evaluations as part of the assessment and treatment of infertility. Moreover, Carr (2011) added that ultrasound assessment begins with the identification of basic gynecologic anatomy and is best observed through a transvaginal approach whenever possible. The cervix, uterus, endometrial lining, and adnexa including the ovaries should be located and measured, and any abnormalities described. In addition, A total agreements was observed between the well trained postgraduate
OBGYN nurses and the infertility clinicians regarding some qualitative uterine and ovarian findings as polycystic ovary (PCO) pictures of both ovaries and visualization of right and left ovaries as Kappa was >0.8 (0.899, 0.889, 0.914, 0.973, respectively) Table 2. However low agreement (Kappa was $0.57 \%, 0.66 \%$ ) was observed regarding the other ovarian findings (Documentation of ovarian response or ovarian cyst) which means more training needed to judge the ovarian response or other ovarian pathology as evident in Table 4. In this context, Atri (2011) emphasized that involvement of nursing staff members in transvaginal ultrasound scanning improving skills and understanding of reproductive endocrinology and reproductive medicine that will be translated into a feeling of competency. This should further increase the nurse's sense of satisfaction as she provides care to the IVF patients, who rely so heavily upon her. National Institute for Health and Care Excellence (2013), Royal College of nursing (2012) \& Sippel et al (2011).

Limitations of the study

The present study is subjected to several limitations such as lack of references and evidence based researches or studies in the same topic. No opportunity to apply the study on large number of nurses as no settled program is available for training nurses and physicians to conduct a comparison between both groups and rely on it.

\section{Conclusions}

With appropriate training almost perfect agreement of Folliculometry findings can be obtained by welltrained postgraduate OBGYN nurses compared to infertility clinicians.

\section{Recommendations}

- Extensive hands on US training program should be held to train fertility clinic nurses especially in Arab countries.

- More researches are needed to investigate the ability of nurses to practice folliculometry compared to infertility clinician and be applied on large numbers of nurses in multiple centers.

Relevance of clinical practice

The extensive and wide use of Folliculometry Ultrasound (FMUS) scan for infertile women in the Ob Gyn clinic motives health care provider especially nurses to have a role in IVF investigation and management, especially in Saudi Arabian conservative culture, in which most women in Gynecologic clinic prefer to be examined by female health care provider rather than males. For that availability of well-trained female nurses in the infertility clinic to do Folliculometry ultrasonography (FMUS) in proper way is highly recommended, 
however lack of training courses for nurses in this context encourage the researcher to start it by training of postgraduate OBGYN nurses who will be responsible for large ongoing program to train high qualified nurses to practice Folliculometry which in turn affect positively to a great extent to nurse's sense of satisfaction as she provides care to the IVF patients who rely so heavily upon her.

\section{Conflict of interest}

We declare that there are no conflicts of interests.

\section{References}

1. A. Rodriguez, R., Vassena, A., Blazquez, J., Guillen, S., Franci, O., Coll, V., Vernaeve. (2014): Training of nurses of assisted reproduction units in 3D folliculometry; abstracts of the 24th World Congress on Ultrasound in Obstetrics and Gynecology, 14-17 September 2014, Volume 44, Issue Supplement S, September, Page 164, Barcelona, Spain.

2. American Institute for US in Medicine, society for reproductive endocrinology and Infertility, American Society of Reproductive Medicine (2009): AIUM practice guideline for ultrasonography in reproductive medicine. J Ultrasound Med. Jan; 28 (1):128-37.

3. American Institute of Ultrasound in Medicine (2012): AIUM practice guideline for the performance of a focused reproductive endocrinology and infertility scan. Laurel, MD: AIUM;

4. American Society for Reproductive Medicine (2009). Nurses performing focused ultrasound examinations in a gynecology/infertility setting (Practice Committee Position Statement). Birmingham, http:/www.asrm.org/guidelines/.

5. Atri Sujatha (2011): Role of Nurse in Invitro Fertilization; The Nursing journal of India; Vol. Cll No. 4

6. AWHONN (2010): Ultrasound examinations performed by nurses in obstetric, gynecologic, and reproductive medicine settings: Clinical competencies and education guide (3rd ed.). Washington, DC.90, 29-30.

7. Barber D., (1994): Continuity of Care in IVF: the nurse's role. Nursing Times. 9-15; 90 (45):29-30.

8. Barnhart K., Coutifaris C., (2000): The use of ultrasound in the evaluation and treatment of infertile women. In: Bluth EI, Arger P, Benson C, Siegel M, Ralls P (eds). The Practice of Ultrasonography. New York NY: Thieme Medical Publishers; 257-269.

9. Bureau of Labor Statistics US Department of Labor. Occupational Outlook Handbook. (2006) 07 editions, registered nurses.
10. Carr S., (2011): Ultrasound for nurses in reproductive medicine. J Obstet Gynecol Neonatal Nurs. Sep-Oct;40(5):638-53.

11. Heidi Birch (2009): The extended role of the nurse - Opportunity or threat? Journal of human fertility; Pages 138-144 Published online: $03 \mathrm{Jul}$

12. Jaynelle F., Stichler (2002): The nurse as consultant; Nursing administration quarterly, vol.26, No.2,.

13. Marry L., McHugh. (2012): Interrater reliability: the kappa statistic. The journal of Croatian Society of Medical Biochemistry and Laboratory Medicine (Biochemia Medica); 22(3):276-82.http://dx.doi.org.

14. Morris E., (2001): The role of infertility nurses in ovulation induction programmes, Hum Fertil (Camb) Women's Health Nurs;4(1):14-7.

15. National Institute for Health and Care Excellence (2013): Clinical guideline -Fertility: assessment and treatment for people with fertility problems, NMC: London. Available from:http://guidance.nice.org.uk/CG156

16. Royal College of nursing (2012): An RCN training and education framework for fertility nursing, RCN: London. Publication code 004 322. Available from:www.rcn.org.uk

17. Stephanie Sippel, Krithika Muruganandan, Adam Levine, \& Sachita Shah (2011): Review article: Use of ultrasound in the developing world; Int J Emerg Med.; 4: 72. doi: 10.1186/1865-1380-4-72 